\title{
Disease-linked connexin26 S17F promotes volar skin abnormalities and mild wound healing defects in mice
}

\author{
Eric Press ${ }^{1}$, Katanya C Alaga ${ }^{2,4}$, Kevin Barr ${ }^{2}$, Qing Shao ${ }^{2}$, Felicitas Bosen ${ }^{3}$, Klaus Willecke ${ }^{3}$ and Dale W Laird ${ }^{*, 1,2}$
}

Several mutant mice have been generated to model connexin (Cx)-linked skin diseases; however, the role of connexins in skin maintenance and during wound healing remains to be fully elucidated. Here we generated a novel, viable, and fertile mouse $\left(\mathrm{C} \times 26^{\mathrm{CK} 14-\mathrm{S} 17 \mathrm{~F} / \mathrm{+}}\right)$ with the keratitis-ichthyosis-deafness mutant (CX26S17F) driven by the cytokeratin 14 promoter. This mutant mouse mirrors several $\mathrm{Cx} 26$-linked human skin pathologies suggesting that the etiology of Cx26-linked skin disease indeed stems from epidermal expression of the $\mathrm{Cx} 26$ mutant. $\mathrm{C} \times 26^{\mathrm{CK} 14-\mathrm{S} 17 \mathrm{~F} / \mathrm{+}}$ foot pad epidermis formed severe palmoplantar keratoderma, which expressed elevated levels of $\mathrm{Cx} 26$ and filaggrin. Primary keratinocytes isolated from $\mathrm{Cx} 26^{\mathrm{CK} 14-\mathrm{S} 17 \mathrm{~F} /+}$ neonates exhibited reduced gap junctional intercellular communication and migration. Furthermore, $\mathrm{Cx} 26^{\mathrm{CK} 14-\mathrm{S} 17 \mathrm{~F} /+}$ mouse skin wound closure was normal but repaired epidermis appeared hyperplastic with elevated expression of cytokeratin 6 . Taken together, we suggest that the Cx26S17F mutant disturbs keratinocyte differentiation and epidermal remodeling following wound closure. We further posit that Cx26 contributes to epidermal homeostasis by regulating keratinocyte differentiation, and that mice harboring a disease-linked Cx26 mutant display epidermal abnormalities yet retain most wound healing properties.

Cell Death and Disease (2017) 8, e2845; doi:10.1038/cddis.2017.234; published online 1 June 2017

Gap junction channels allow for direct intercellular communication by facilitating the passage of small molecular messengers between the cytosol of adjacent cells. ${ }^{1}$ Individual cells may also exchange signaling molecules with the extracellular environment through hemichannels at the cell membrane. $^{2}$ Gap junction channels are composed of docked hemichannels from adjacent cells, each of which contains six oligomerized connexin (Cx) subunits. Connexins comprise a family of transmembrane proteins that have large clinical significance due to the discovery of many disease-causing mutations within connexin encoding genes. Mutations in the genes encoding Cx26, Cx30, Cx30.3, Cx31, and Cx43 are extensively linked to a variety of hereditary skin diseases. ${ }^{3,4}$ Notably, mutations in the genes encoding Cx26 and Cx30 cause syndromic diseases where patients suffer from hearing loss and a broad range of skin abnormalities that vary in localization and severity. ${ }^{3,5,6}$ Interestingly, Cx26 mutants with similar functional characteristics often lead to comparable phenotypes, suggesting specific functional anomalies are closely tied to disease outcomes. ${ }^{5,7}$ Not surprisingly, Cx26 is expressed in the cochlea and epidermis, and shares a similar localization pattern with $\mathrm{Cx} 30$ in the epidermal strata, ${ }^{8}$ and likely form heteromeric channels between keratinocytes.

The human epidermis expresses up to 7 distinct connexin proteins in overlapping populations of keratinocytes highlighting the complexity of gap junctional intercellular communication (GJIC) in this tissue. ${ }^{9}$ Genetically modified mouse models previously demonstrated that persistent epidermal Cx26 expression promoted a hyperproliferative, inflammatory response suggesting a delicate balance of individual connexins may be required for epidermal health. A key factor likely involved in regulating keratinocyte differentiation is an increasing intracellular $\mathrm{Ca}^{2+}$ gradient between keratinocytes of the stratum basale and stratum granulosum. ${ }^{10,11}$ Gap junction channels are known to pass signaling molecules such as $\mathrm{IP}_{3}$ that regulate intracellular $\mathrm{Ca}^{2+}$ handling, which may have a profound influence on the synthesis and assembly of skin barrier components such as filaggrin and ceramides. ${ }^{12,13}$ Furthermore, it is well known that following cutaneous wounding, multiple connexins including Cx26, Cx30, and Cx43, are dynamically regulated within the epidermis suggesting they have a major role in coordinating wound healing events such as keratinocyte proliferation, migration, and differentiation. ${ }^{14,15}$ In fact, numerous studies employing Cx43 knockdown strategies have demonstrated beneficial wound healing outcomes, ${ }^{16-20}$ which strongly promotes $\mathrm{Cx} 43$ as a therapeutic target for chronic wounds. Despite the evidence supporting the influence of connexins on epidermal health, the role of $\mathrm{Cx} 26$ in the skin is not completely understood, particularly in the context of healing wounds.

Several Cx26 mutants, including the S17F mutant, are linked to keratitis-ichthyosis-deafness syndrome (KIDS); a rare and severe autosomal dominant disease featuring generalized dry/scaly skin, patchy erythematous keratoderma and palmoplantar keratoderma (PPK). ${ }^{21}$ In some cases, frequent cutaneous infections lead to fatal septicemia early in life. ${ }^{21}$ In vitro ectopic expression studies have revealed hyperactive or 'leaky' hemichannels as a likely pathogenic characteristic of KIDS mutants. ${ }^{22,23}$ Interestingly, the S17F mutant does not form functional gap junction channels or

\footnotetext{
${ }^{1}$ Department of Physiology and Pharmacology, University of Western Ontario, London, ON, Canada; ${ }^{2}$ Department of Anatomy and Cell Biology, University of Western Ontario, London, ON, Canada and ${ }^{3}$ LIMES (Life and Medical Sciences Institute), Molecular Genetics, University of Bonn, Bonn, Germany

*Corresponding author: DW Laird, Department of Anatomy and Cell Biology, University of Western Ontario, London, ON, Canada N6A 5C1. Tel: +519 661-2111 x86827; Fax: +519 8502562; E-mail: dale.laird@schulich.uwo.ca

${ }^{4}$ Contributed significantly to this work.

Received 09.12.16; revised 20.3.17; accepted 21.3.17; Edited by E Candi
} 

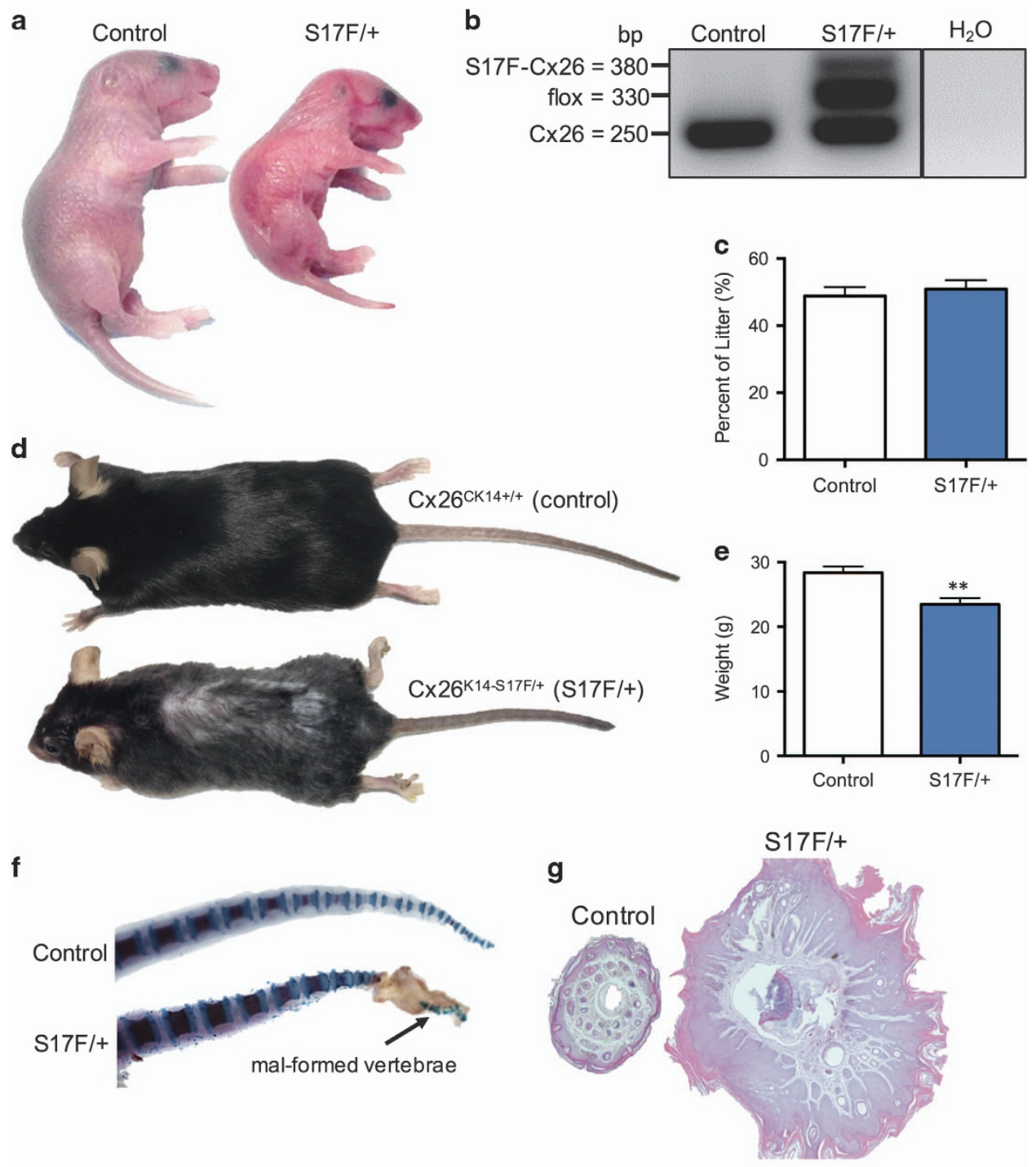

h

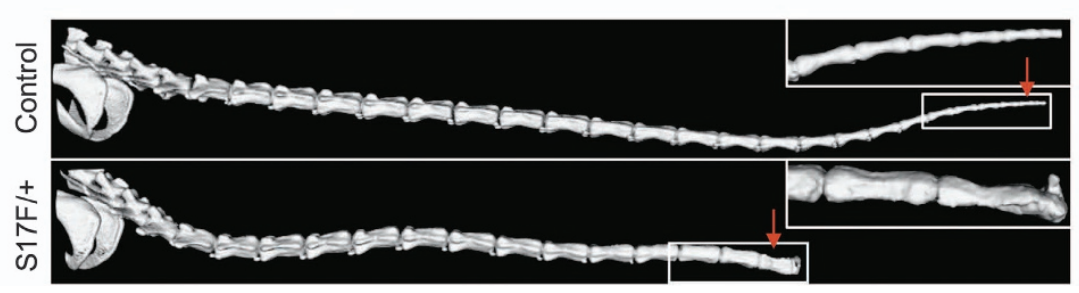

Figure $1 \mathrm{~S} 17 \mathrm{~F} /+$ mice mimic KIDS skin characteristics and have several additional phenotypes. (a) S17F/+ neonates were smaller and visually distinguishable from control littermates. (b) Skin sample PCR amplification confirms the heterozygous expression of Cx26S17F in S17F/+ mice. (c) Litters contained equal portions of S17F/+ and control pups with no loss of mouse viability (unpaired $t$-test, Control: $n=157$, S17F/t: $n=148$ ). (d) Representative photos of 3-month-old S17F/+ and control mice reveal moderate differences in size but a pronounced tail phenotype. (e) Whole mouse weights at 3 months of age showed S17F/+ mice were $\sim 15 \%$ smaller (unpaired $t$ test, ${ }^{\star *} P<0.01, N=17$ ). (f) Skeletal stains of P7 tails revealed vertebral malformations underlying the tail phenotype in S17F/+ mice. (g) Cross-section of a distal tail paraffin section stained with hematoxylin and eosin revealed grossly thickened epidermis. (h) $\mu \mathrm{CT}$ scans of 3-month-old mouse tails revealed vertebral abnormalities in S17F/+ mice. Red arrows in (h) denote the relative locations of cross sections in $(\mathbf{g})$

hemichannels on its own, ${ }^{22,24}$ but rather forms heteromeric hyperactive hemichannels when co-expressed with wild-type Cx26 or Cx43 (ref. 22). To understand how these molecular traits translate in vivo, a mutant mouse that globally expresses the S17F mutant replicates several KIDS phenotypes in addition to features typically associated with separate Cx26- linked diseases. ${ }^{25}$ However, because these mice have low viability and it is still unknown how the mutant specifically affects the epidermis, we generated a tissue-specific mouse that harbors the S17F mutant in the epidermis $\left(\mathrm{C} \times 26^{\mathrm{CK} 14-\mathrm{S} 17 \mathrm{~F} /+}\right)$. Although numerous abnormal cellular characteristics of $\mathrm{Cx} 26$ mutants have been identified, and several mutant mice have 
been generated to model human connexin-linked skin disorders, the etiology of these diseases as well and their impact on cutaneous wound healing remains poorly understood.

Therefore, by using our novel Cx26 ${ }^{\mathrm{CK} 14-\mathrm{S} 17 \mathrm{~F} /+}$ mouse (hereafter noted as S17F/+), we aimed to assess how Cx26S17F produces skin disease, and to gain further insight into the role of Cx26 in healthy skin. We found that Cx26S17F, produced severe PPK, wherein expression of Cx26 as well as filaggrin was elevated in foot pad skin indicating deregulated differentiation. Moreover, primary keratinocytes from Cx26 ${ }^{\mathrm{CK} 14-\mathrm{S} 17 \mathrm{~F} /+}$ mice had reduced gap junctional coupling and reduced migration. Lastly, Cx26 mutant mice displayed abnormal epidermal remodeling following wound closure but retained most of the properties associated with active wound healing.

\section{Results}

Epidermal expression of Cx26S17F results in severe skin features plus comorbidities. S17F/+ mice harboring the mutated Gjb2 gene in cells expressing cytokeratin 14 (basal keratinocytes) resulted in a conditional mutant mouse that expressed the S17F mutant under the control of the endogenous Cx26 promoter in cells of the keratinocyte lineage. This expression profile was capable of reproducing KIDS skin features in a novel mutant mouse in addition to several intriguing phenotypes (Figure 1). S17F/+ pups were visibly smaller and had red, dry, scaly skin (Figure 1a). PCR analysis of skin tissue confirmed the heterozygous expression of Cx26S17F (Figure 1b). Contrary to global Cx26 ${ }^{\mathrm{S} 17 \mathrm{~F} /+}$ mice, ${ }^{25}$ our tissue-defined $\mathrm{S} 17 \mathrm{~F} /+$ mice had no loss of viability and were born in equal proportion to wild-type littermates (Control) (Figure 1c). Interestingly, S17F/+ mice were approximately $15 \%$ smaller by 3 months of age (Figure 1e), and had a shortened tail (Figure 1d) which coincided with the formation of a cutaneous bulb at the distal tail by post-natal day 7 (Figures $1 \mathrm{f}$ and $\mathrm{g}$ ). This appeared to impair proper vertebral formation within the bulb preventing normal tail growth (Figure 1h).

Cx26 ${ }^{\mathrm{CK} 14-\mathrm{S} 17 \mathrm{~F} /+}$ neonates display a functional epidermal barrier. To test the epidermal barrier of the S17F/+ mice, we submerged euthanized neonates in an aqueous toluidine blue solution and observed epidermal staining. We found that similar to littermate controls, S17F/+ epidermis did not stain blue indicating little to no epidermal penetration of the watersoluble dye (Figure 2). However, epidermal staining was evident in areas of the skin that had been cut, or treated with acetone (Figure 2) which disrupts lipids in the epidermal barrier. ${ }^{26}$ This suggests that neonatal $\mathrm{S} 17 \mathrm{~F} /+$ epidermis indeed forms an effective water barrier.

Cx26S17F disrupts keratinocyte differentiation in foot pad epidermis. Severe PPK was clearly visible in adult $\mathrm{S} 17 \mathrm{~F} /+$ mice in which foot pad epidermis displayed protruding hyperpigmented calluses (Figure 3a). Histological examination confirmed a gross thickening of vital epidermal layers (stratum basale, spinosum, and granulosum) (Figures 3a

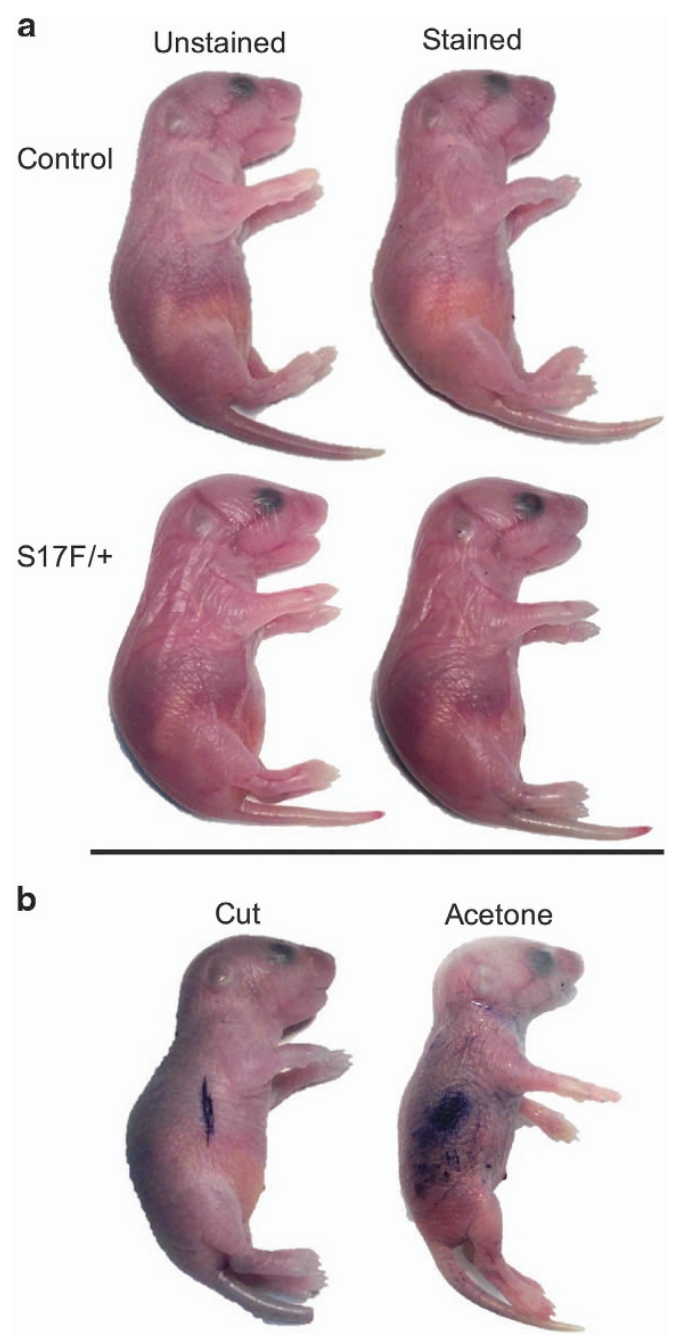

Figure 2 S17F/+ neonates display an intact epidermal barrier. P2 neonates were submerged in an aqueous toluidine blue solution to assess epidermal barrier permeability. Similar to control littermates, S17F/+ neonates displayed no epidermal staining indicating a functional barrier (a). To demonstrate epidermal staining from a defective barrier, neonatal epidermis was cut or treated with acetone (b). $N=6$

and $\mathrm{b}$ ). In addition to the bulbous region at the distal tail, middle regions of tail epidermis also displayed moderate thickening of these vital layers (Figure $3 b$ ).

Tissue lysates of hind foot pad skin from 3-month-old S17F/ + mice showed elevated levels of Cx26 (Figure 4a). While no differences in $\mathrm{C} \times 30$ or $\mathrm{C} x 43$ levels were detected in mutant epidermis, all three connexins had large overlapping distribution profiles that were clearly distinguishable from control epidermis (Figure 4b). Each connexin formed abundant gap junction plaques indicating that the Cx26S17F mutant does not impair connexin trafficking in vivo. S17F/+ epidermis also had normal levels of cytokeratin 14 (expressed in basal keratinocytes) but a greater amount of filaggrin (expressed in the stratum granulosum and corneum) which was found in numerous suprabasal keratinocyte layers (Figures $5 a$ and b). Epidermal proliferation was not affected based on Ki67 (Figure 5c) and proliferating cell nuclear antigen (PCNA) assessment (Figure 5d). Together these findings suggest 

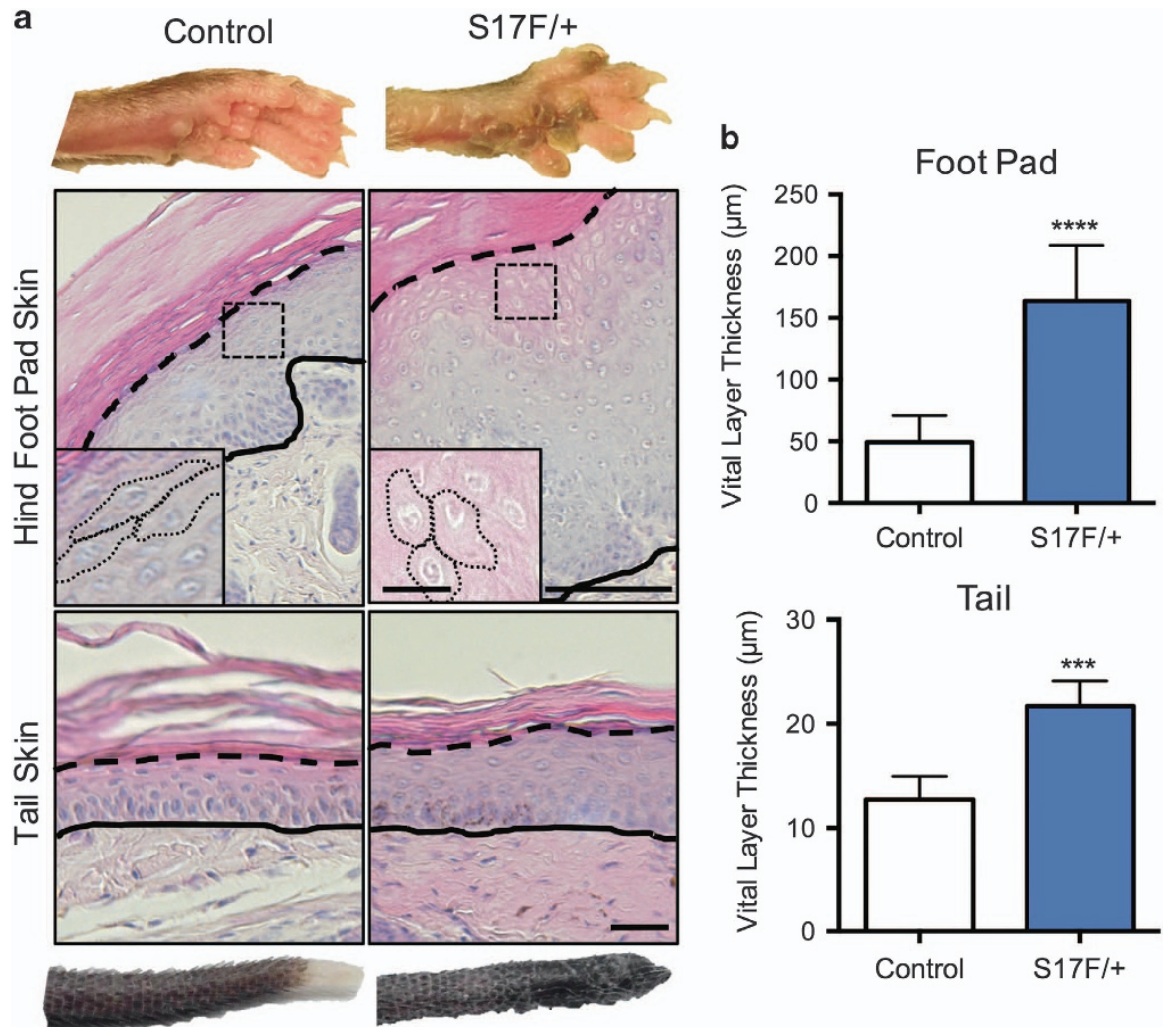

Figure $3 \mathrm{~S}$ S17F/+ mice display thicker foot pad and tail epidermis. (a) 3-month-old S17F/+ mice exhibit severe foot pad epidermal thickening including abnormal nonsquamous keratinocytes in suprabasal layers (insets) as well as thicker tail epidermis compared to controls (b) (unpaired $t$-test, ${ }^{* * *} P<0.001,{ }^{* * \star *} P<0.0001, N=7$ ). Complete and dashed lines denote the dermis-epidermis boundary and stratum granulosum-corneum boundary, respectively. Scale bar in (a) (upper), $50 \mu \mathrm{m}$ (inset =10 $\mu \mathrm{m}$ ); (a) (lower), $10 \mu \mathrm{m}$

epidermal Cx26S17F disrupts keratinocyte differentiation and promotes the formation of PPK in mice.

Primary keratinocytes harvested from $\mathrm{S} 17 \mathrm{~F} /+$ mice exhibit reduced GJIC and collective cell migration. Keratinocytes were harvested from newborn mice to assess the influence of physiological regulation of Cx26S17F on keratinocytes. Similar to a well-characterized rat epidermal keratinocyte (REK) cell line (Supplementary Figure 1A), nearly all primary mouse keratinocytes labeled thoroughly with cytokeratin 14 and intermediate filaments were clearly visible under high magnification (Supplementary Figure 1B), indicating a highly pure keratinocyte population. In dense clustered regions, cells stratified and increased filaggrin expression, mimicking the behavior of stratified keratinocytes in live epidermis (Supplementary Figure 1B). Keratinocyte cultures were incubated in media containing $1.4 \mathrm{mM} \mathrm{CaCl}_{2}$ for $24 \mathrm{~h}$ to stimulate differentiation and the subsequent expression of Cx26. Compared with controls, S17F/+ cultures appeared to form fewer and smaller Cx26 gap junction plaques between cells, and demonstrated reduced fluorescence recovery following photobleaching (Figures $6 a$ and $b$ ). Furthermore, S17F/+ cultures displayed reduced collective migration in response to scratch wounds (Figure 6c). Together these findings suggest Cx26 intercellular communication may influence keratinocyte migration.
S17F/+ mice retain most cutaneous wound healing properties. Since dynamic regulation of Cx26 coincides with different stages of wound healing, we tested whether S17F/+ mice displayed any overt wound healing defects. Between 3 and 4 months of age, a punch biopsy of depilated dorsal skin created a wound in which healing was monitored. S17F/+ mice displayed no differences in wound size at any stage of recovery (Figure 7a), however repaired epidermis at 14 days post-wounding was measurably thicker in S17F/+ mice suggesting possible aberrant epidermal remodeling in response to the wound (Figure 7b). Repaired epidermis also exhibited strong cytokeratin 6 and Ki67 expression (Figure 8a) similar to murine skin exhibiting dermatitis (Figure 8b). There were also no detectible differences in inflammatory cell invasion between control and S17F/+ repaired epidermis 14 days post-injury (Supplementary Figure 2).

\section{Discussion}

Connexin-linked skin diseases encompass a diverse array of congenital skin abnormalities wherein patients express connexin mutants with defects in cellular communication. ${ }^{27}$ Mouse models harboring connexin modifications have demonstrated that the epidermis relies on complex GJIC to coordinate a balance of cell proliferation and differentiation 
a
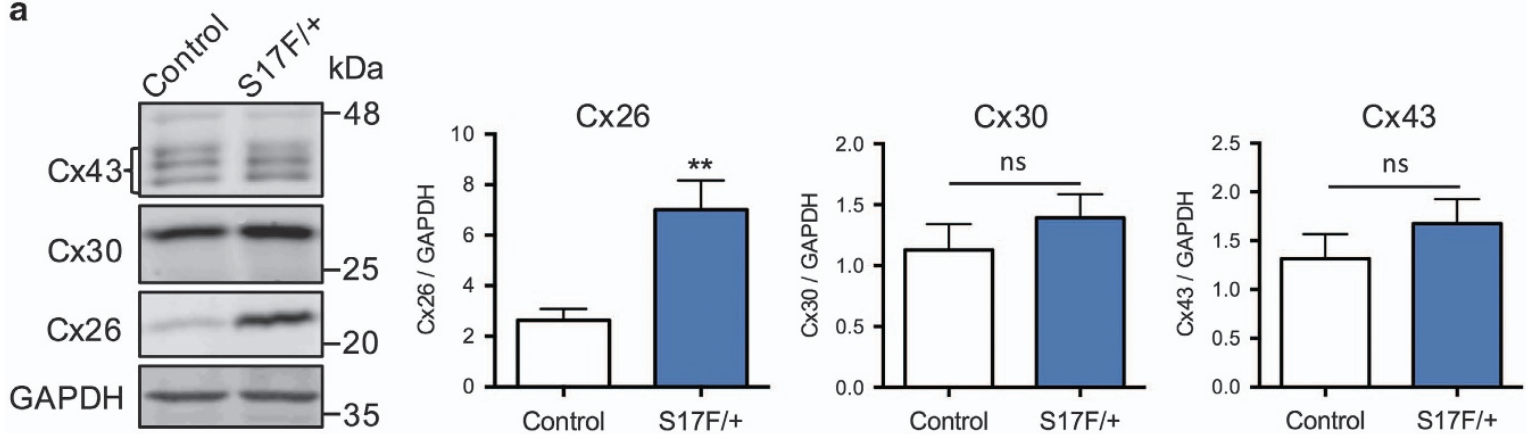

b

$\mathrm{Cx} 26$

$\mathrm{C} \times 30$
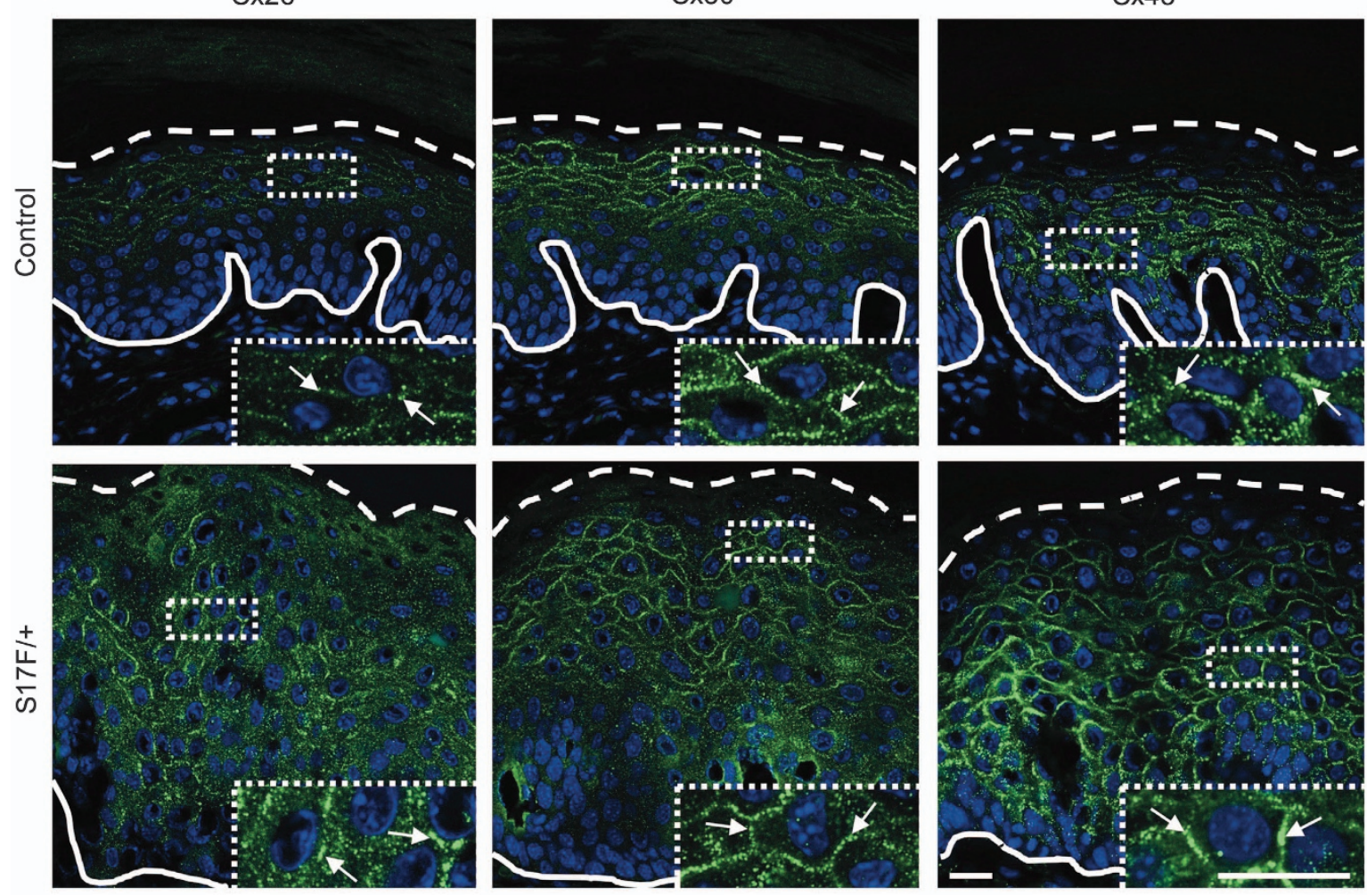

Figure $4 \mathrm{~S} 17 \mathrm{~F} /+$ foot pad skin exhibits deregulated connexin expression. (a) Foot pad skin lysates from 3-month-old S17F/+ mice exhibited elevated levels of Cx26 expression compared to controls (unpaired $t$-test, ${ }^{* \star} P<0.01$, ns $=P>0.05, N=10$ ). (b) Cryosections of 3-month-old S17F/+ foot pad epidermis revealed that $\mathrm{C} \times 26, \mathrm{C} \times 30$, and Cx43 formed abundant gap junctions in a broad range of keratinocyte layers. Complete and dashed lines denote the dermis-epidermis boundary and stratum granulosumcorneum boundary, respectively. Scale bar, $20 \mu \mathrm{m}$ (inset $=20 \mu \mathrm{m}$ )

for the maintenance of rapid physiological turnover and resiliency to injury. ${ }^{16,25,28-32}$ Of particular interest are Cx26 and Cx30 linked skin diseases due to the large number of distinct gene mutations that lead to syndromic diseases featuring variable skin disorders. ${ }^{5}$ Patients dominantly expressing the Cx26S17F mutant are diagnosed with KIDS and display severe hearing, ocular, and skin phenotypes. ${ }^{24,33}$ Although mutant Cx26 undoubtedly underpins this disease, specific pathogenic mechanisms are poorly understood and the question of whether these patients have wound healing defects has not been explored. In this study, we generated a novel keratinocyte-specific $\mathrm{Cx} 26^{\mathrm{CK} 14-\mathrm{S} 17 \mathrm{~F} /+}$ mouse to address these questions. We found that $\mathrm{S} 17 \mathrm{~F} /+$ mice developed severe PPK wherein foot pad epidermis exhibited increased Cx26 expression and irregular localization profiles of epidermal connexins. Furthermore, S17F/+ foot pad epidermis exhibited elevated filaggrin expression, but normal expression of cytokeratin 14 and displayed normal proliferation. Primary keratinocytes isolated from connexin mutant neonates revealed altered GJIC and migration abilities in culture. S17F/+ skin exhibited aberrant epidermal remodeling during wound healing but wounds healed at a similar rate to littermate control mice.

Cx26S17F was first linked to KIDS in 2002 (ref. 24) and is now understood to form non-functional gap junction channels or hemichannels but does form hyperactive heteromeric 
a

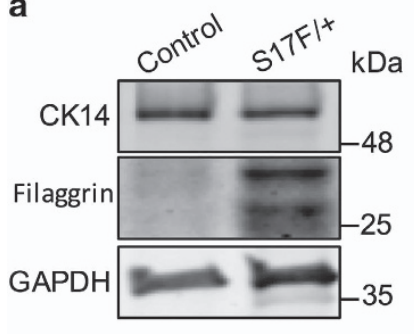

b

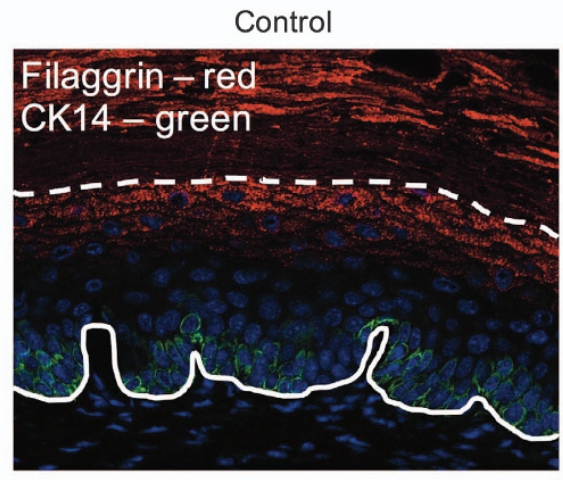

C

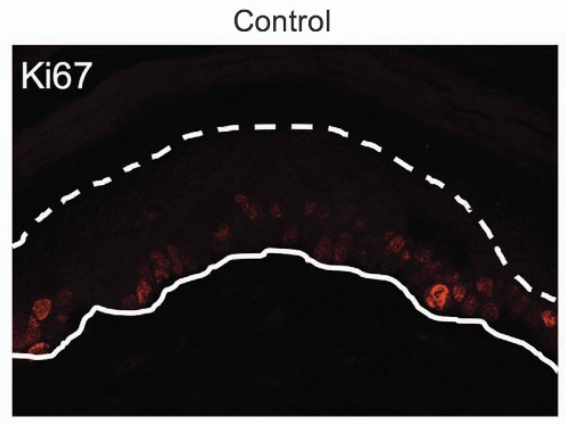

d

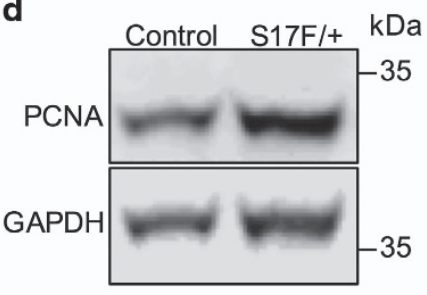

CK14

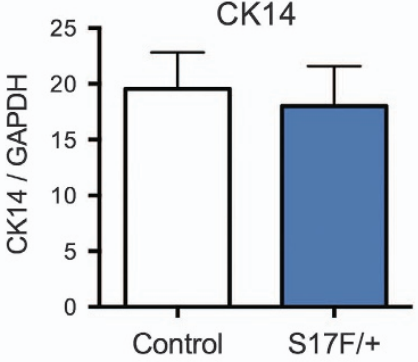

Filaggrin

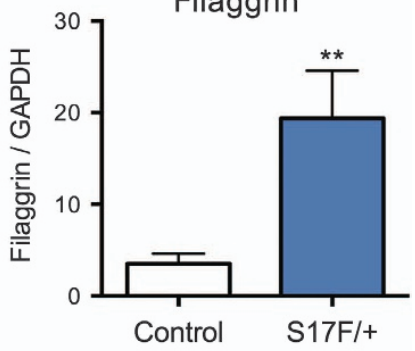

S17F/+

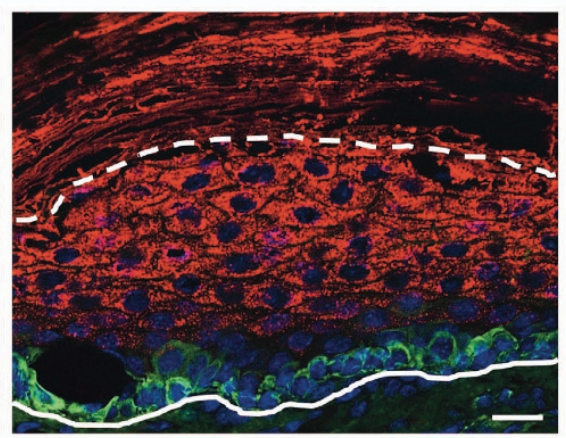

S17F/+
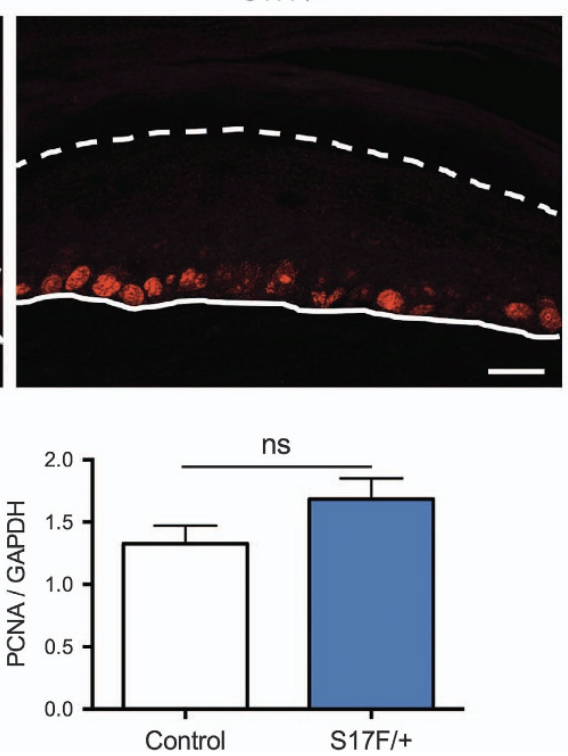

Figure $5 \mathrm{~S}$ S17F/+ mice display abnormal keratinocyte differentiation in foot pad epidermis. (a) Foot pad skin lysates from 3-month-old S17F/+ mice have elevated filaggrin, but normal keratin 14 levels compared with controls (unpaired $t$-test, ${ }^{* \star} P<0.01, N=10$ ). (b) 3-month-old foot pad epidermis labeled for filaggrin (red) and cytokeratin 14 (green) revealed elevated filaggrin labeling of suprabasal keratinocytes in S17F/+ epidermis. (c) 3-month-old foot pad epidermis labeled for Ki67 (red) and lysates immunoblotted for PCNA (d) demonstrated unaltered levels of cell proliferation in S17F/+ epidermis (unpaired $t$-test, $n s=P>0.05, N=10$ ). Complete and dashed lines denote the dermisepidermis boundary and stratum granulosum-corneum boundary, respectively. Scale bar in ( $b$ and $\mathbf{c})=20 \mu \mathrm{m}$

hemichannels with wild-type Cx26 and Cx43 in culture. ${ }^{22}$ Many syndromic Cx26 mutants fail to form functional channels, ${ }^{7}$ however studies investigating separate KIDS linked mutants reveal that hyperactive hemichannels may be a strong etiological factor in KIDS. ${ }^{22,23,34}$ A mutant mouse globally expressing Cx26S17F was found to replicate KIDS skin and hearing phenotypes making it a suitable model for
KIDS. ${ }^{25}$ However, one drawback with this model was a sharp loss of mouse viability. To alleviate this concern and to directly assess the role of the Cx26S17F mutant in the epidermis, we generated a keratinocyte-specific mutant mouse driven by the cytokeratin 14 promoter. We showed here that indeed epidermal expression of Cx26S17F produced the severe PPK seen in KIDS, as well as a short, blunted tail reminiscent 

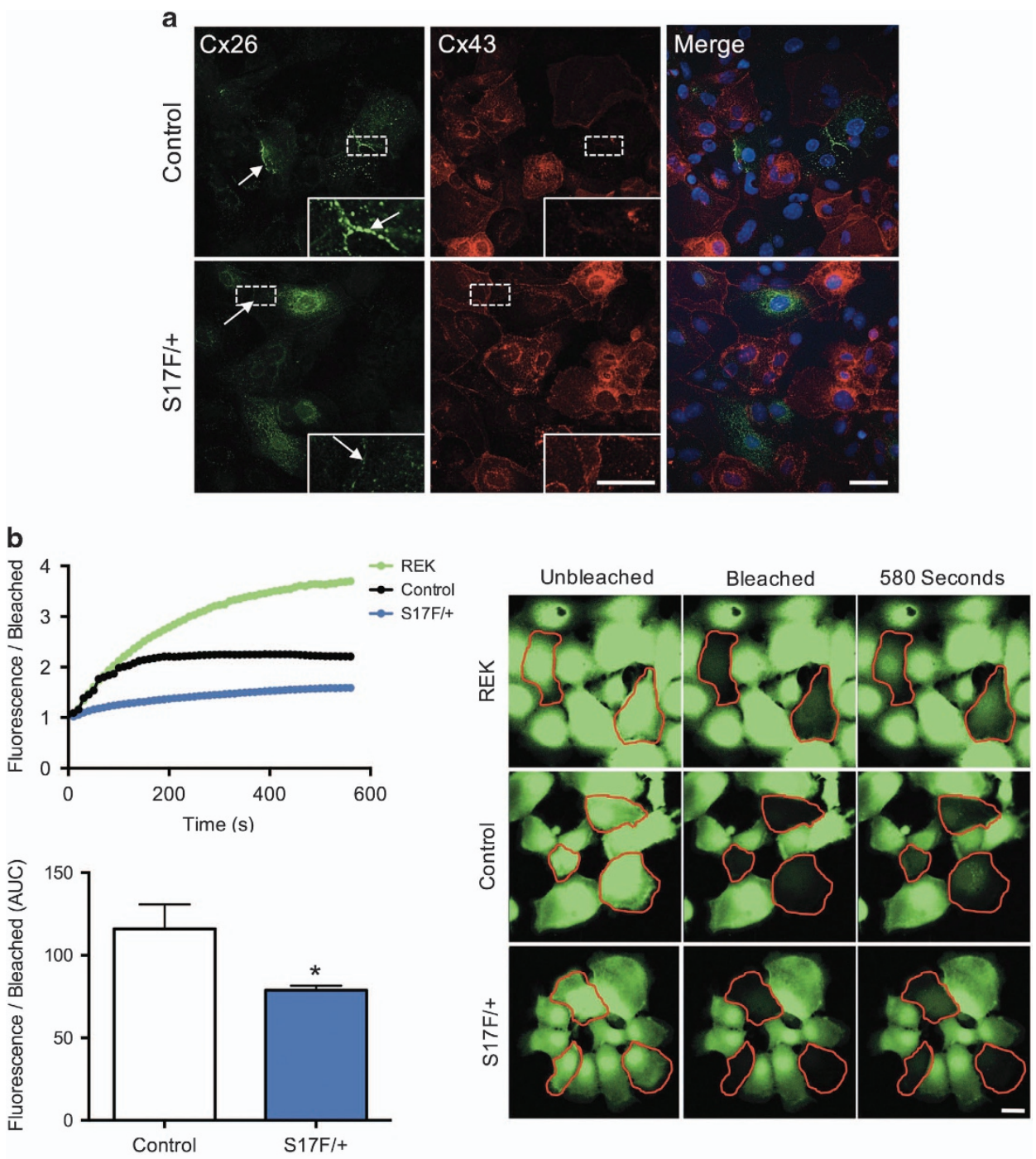

C
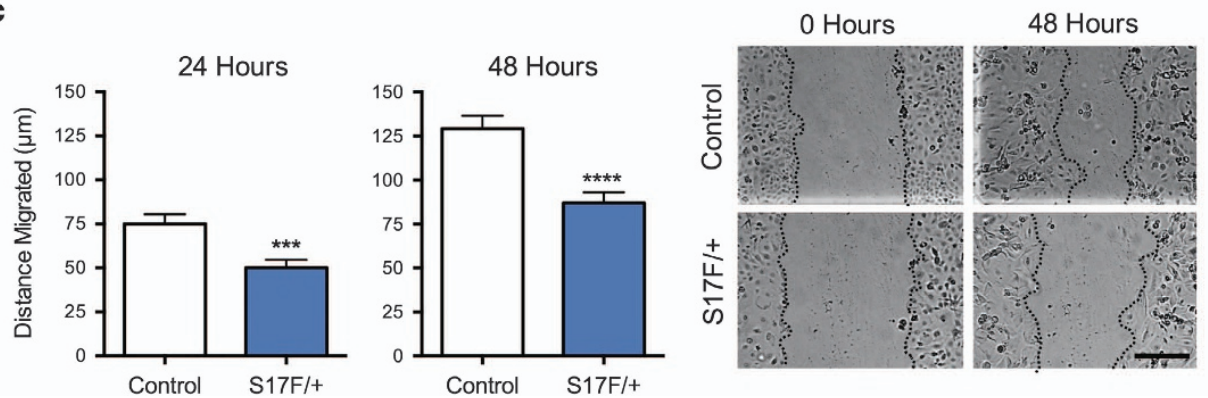

Figure 6 Keratinocytes isolated from S17F/+ neonates have reduced GJIC and collective cell migration. (a) S17F/+ keratinocyte cultures appeared to form fewer and smaller Cx26 gap junctions between cells. (b) S17F/+ keratinocytes have reduced calcein-AM fluorescence recovery after photobleaching compared to controls indicative of reduced GIC (photobleached cells are outlined in red) (unpaired $t$-test, ${ }^{*} P<0.05, N=3$ ). (c) Collective keratinocyte migration in response to scratch wounds was reduced in $\mathrm{S} 17 \mathrm{~F} /+$ cultures compared to controls (unpaired $t$-test, $\left.{ }^{* \star *} P<0.001,{ }^{* \star * *} P<0.0001, N=4\right)$. Scale bar in $(\mathbf{a})=20 \mu \mathrm{m}$ (inset $\left.=10 \mu \mathrm{m}\right),(\mathbf{b})=10 \mu \mathrm{m},(\mathbf{c})=100 \mu \mathrm{m}$

of autoamputated digits in patients with the Cx26-linked Vohwinkel Syndrome. ${ }^{35}$ Furthermore, Cx26 $6^{\mathrm{CK} 14-\mathrm{S} 17 \mathrm{~F} /+}$ mice in this study were generally healthy suggesting that expression of the S17F mutant in other tissues such as liver, kidney, brain, and gut may have contributed to reduced viability seen in mice with global expression of the S17F mutant. We also showed that Cx26 ${ }^{\mathrm{CK} 14-\mathrm{S} 17 \mathrm{~F} /+}$ mice had an intact epidermal barrier as evaluated by using the exact protocol from Schütz et al. ${ }^{25}$ This observation was surprising and suggested that Cx26S17F expression in embryonic tissues may interfere with the establishment of the epidermal barrier in utero and contribute to their poor prognosis. Cx26 is indeed expressed 


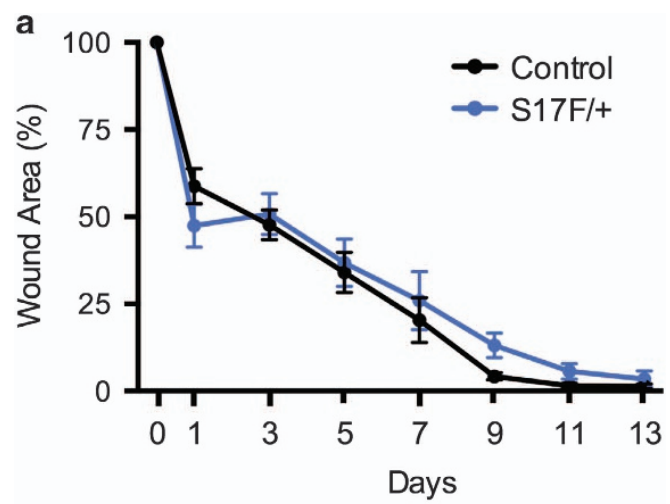

b
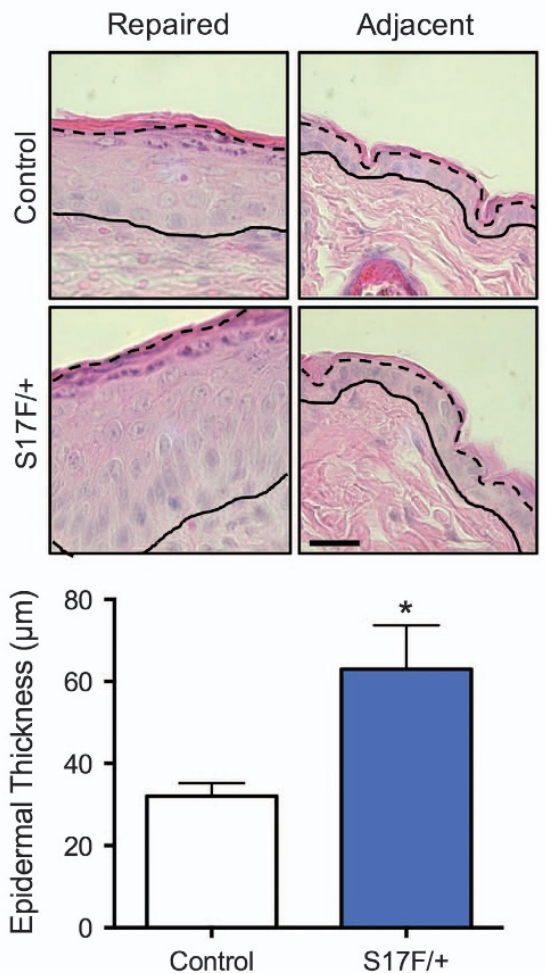

Figure 7 S17F/+ mice display normal wound closure, but exhibit abnorma epidermis remodeling. (a) Dorsal skin wound closure was found to be similar between S17F/+ mice and controls (c) (two-way ANOVA with repeated measures), however, epidermis remodeling following wound closure generated thicker epidermis in $\mathrm{S} 17 \mathrm{~F} /+$ mice compared with controls (b) (unpaired $t$-test, ${ }^{*} P<0.05, N=4$ ). Scale bar, $10 \mu \mathrm{m}$

in the labyrinth layer of the fetal mouse placenta and interestingly, Cx26 null embryos die by 11 days post conception due to a placental defect. ${ }^{36}$ Direct empirical comparison of the development of global and conditional mutant mice may shed light on the nature of the barrier defect and loss of viability in global mutant mice, and could further point to developmental complications in patients who harbor KIDS mutations. Nevertheless, the Cx26 $6^{\mathrm{CK} 14-\mathrm{S} 17 \mathrm{~F} /+}$ mouse model allowed us to evaluate the influence of the Cx26S17F mutant on the epidermis alone, and whether this expression profile can disrupt wound healing which involves numerous unaffected cell types such as fibroblasts, leukocytes, and endothelial cells.
The nearly universal feature of PPK in connexin-linked skin diseases suggests that proper GJIC is crucial to maintain highly stratified volar epidermis. ${ }^{3}$ We found an imbalance of keratinocyte proliferation and differentiation in foot pad epidermis of $\mathrm{S} 17 \mathrm{~F} /+$ mice indicated by increased filaggrin expression yet normal expression of Ki67 and PCNA. Since filaggrin condenses the keratin cytoskeleton in differentiated keratinocytes, we surprisingly observed that suprabasal keratinocytes from S17F/+ foot pad skin did not appear to adopt a squamous morphology like those in control epidermis. We also showed that $\mathrm{Cx} 26, \mathrm{Cx} 30$, and $\mathrm{Cx} 43$ were not confined to specific keratinocyte layers but rather were expressed in most keratinocytes, further suggesting deregulated differentiation. Calcium homeostasis in the epidermis is thought to have a large impact on keratinocyte differentiation, ${ }^{10}$ and since $\mathrm{Ca}^{2+}$ mobilizing molecules such as $\mathrm{IP}_{3}$ and ATP are permissible by gap junctions and hemichannels, the calcium profile in lesioned epidermis is an attractive, albeit difficult element to assess. Interestingly, Bosen and colleagues showed that unlike control littermates, global $\mathrm{C} \times 26^{\mathrm{S} 17 \mathrm{~F} /+}$ mice exhibited large amounts of $\mathrm{Ca}^{2+}$ in the stratum corneum, suggesting that Cx26S17F may disrupt the calcium profile in the epidermis. ${ }^{12}$ As some connexin hemichannels are known to release ATP in response to mechanical stimulation, ${ }^{2,37,38}$ it is plausible that mutant connexins in the mechanical environment of volar skin could stimulate aberrant purinergic signaling that disrupts $\mathrm{Ca}^{2+}$ homeostasis and finally differentiation. ${ }^{38,39}$ Furthermore, lesions of flexural skin regions are also commonly observed in KIDS and Vohwinkel Syndrome patients $^{3,21}$ further supporting mechanically stimulated Cx26 mutants in skin pathogenesis. Nevertheless, investigations into the mechanical sensitivity of Cx26 mutants are warranted to shed light on this notion.

Keratinocytes isolated from conditional Cx26 $\mathrm{CK} 14-\mathrm{S} 17 \mathrm{~F} /+$ mice demonstrated that physiological levels of the Cx26S17F mutant led to reduced gap junctional coupling and a similar reduction in collective cell migration. Following wounding, undamaged keratinocytes at the wound edge initiate reepithelialization by migrating under the coagulum. ${ }^{40}$ During this process, a transient reduction of cell surface Cx43 favors cell migration by reducing cell-cell adhesion through its binding partner zona occludens-1, a protein linked to junctional complexes. ${ }^{41}$ Our results suggest that Cx26, which is thought to bind an ubiquitin-ligase protein $^{42}$ can also influence cell migration through direct intercellular communication. Despite being well documented, the transient upregulation of $\mathrm{Cx} 26$ in keratinocytes at the wound edge is poorly understood. ${ }^{17,43-45}$ However, our results suggest this may generate a highly coupled keratinocyte network to optimize collective cell migration. To our surprise, S17F/+ keratinocyte cultures also appeared to form fewer and smaller gap junction plaques in light of extensive Cx26 gap junction formation in intact S17F/+ epidermis. However, reduced gap junction formation by $\mathrm{Cx} 26 \mathrm{~S} 17 \mathrm{~F}$ has been reported in HeLa cells, ${ }^{22}$ therefore the disparagement of connexin expression between native epidermis and in vitro models highlights the importance of using mutant mouse models for understanding connexin-linked pathologies.

Because Cx26 is dynamically regulated during wound healing $^{14}$ and KIDS patients develop inflammatory skin 

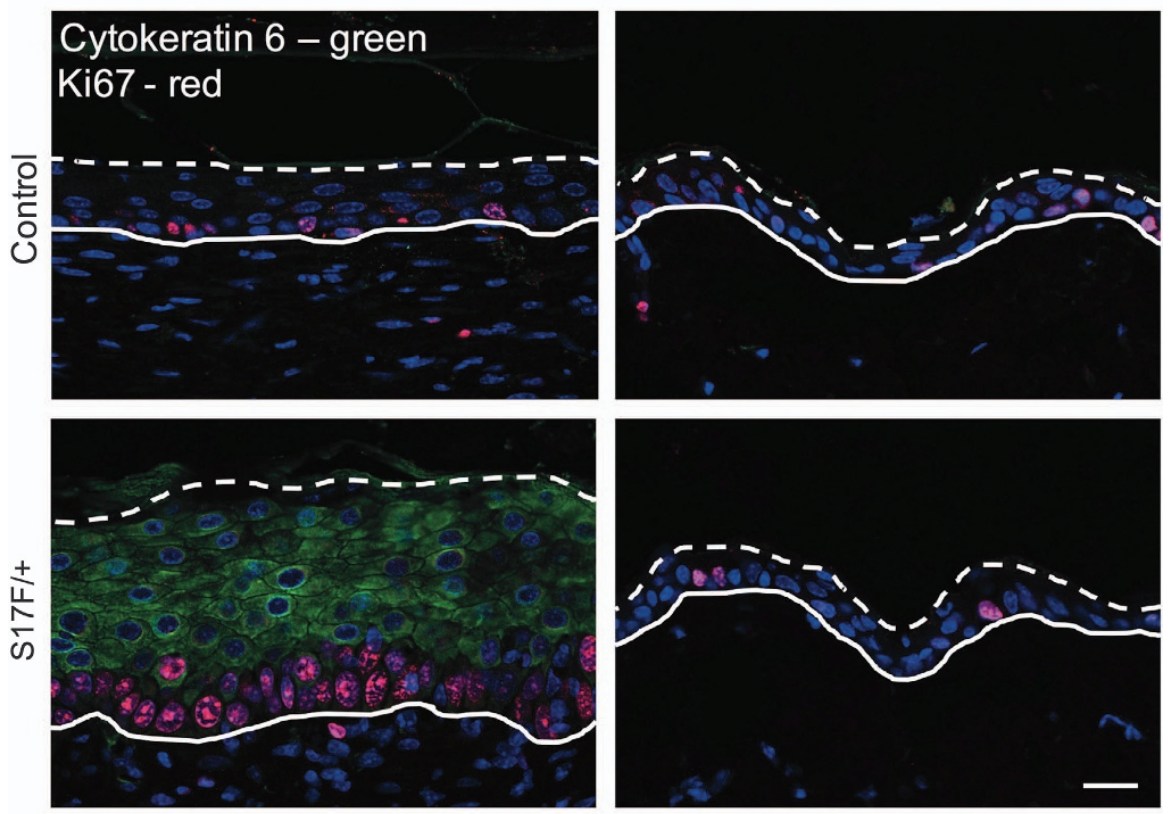

b

Dermatitis

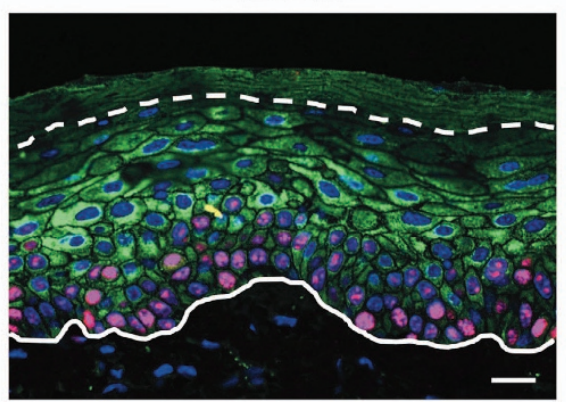

Wound Edge

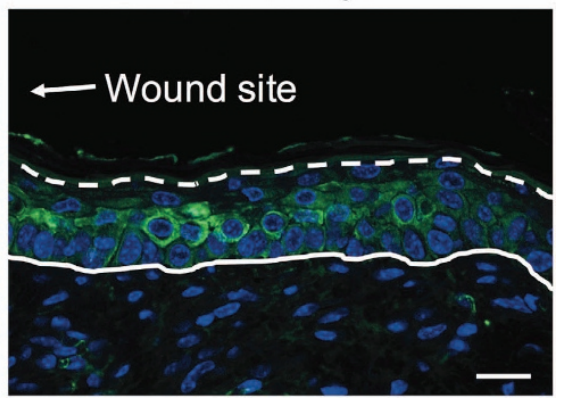

Figure 8 Repaired S17F/+ epidermis displays activated keratinocytes 14 days following wounding. (a) Repaired S17F/+ epidermis revealed prominent expression of cytokeratin 6 (green) and Ki67 (red) indicating activated keratinocytes similar to skin exhibiting dermatitis (b). Cytokeratin 6 expression diminishes at the wound edge (b). Scale bar in $(\mathbf{a}$ and $\mathbf{b})=20 \mu \mathrm{m}$

lesions, ${ }^{21}$ it raises questions as to whether KIDS patients have abnormal wound healing. There are currently no reports of KIDS patients exhibiting wound healing defects; however, the protective care these patients require ${ }^{21}$ and the rare nature of this disease argues that a wound healing defect may be under reported. In one study linking Cx26 levels to wound healing, mouse models with persistent epidermal Cx26 expression developed inflammatory lesions and wounds which displayed improper remodeling ${ }^{30}$ suggesting that $\mathrm{Cx} 26$ may contribute to the inflammatory and remodeling phases of wound healing. However, the S17F/+ mice used in our study displayed no overt wound closure defects nor evidence of differences in inflammatory cell invasion. However, further examination of repaired $\mathrm{S} 17 \mathrm{~F} /+$ epidermis revealed prominent cytokeratin 6 and Ki67 expression indicating activated keratinocytes and a possible delay in the transition to normal keratinocyte differentiation. ${ }^{46}$ Despite this, if our findings can be extrapolated to humans, it would suggest that KIDS patients might only display mild defects in cutaneous wound repair.
Lastly, we also demonstrated that hyperkeratotic foot pad epidermis in S17F/+ mice had elevated levels of Cx26, suggesting that while unchallenged skin was relatively normal, skin challenged by weight bearing or wound healing may provide the conditions for the Cx26S17F mutant to disrupt epidermal physiology. Although the exact nature of these conditions remains uncertain, our findings support the notion that Cx26S17F disrupts epidermal homeostasis by deregulating keratinocyte differentiation. Despite subtle differences between murine and human epidermis, our findings strongly support the generation and assessment of animal models that mirror connexin-linked diseases. Fortunately, five mouse models feature GJB2 modifications have helped elucidate the pathogenesis of KIDS and Vohwinkel Syndrome, ${ }^{25,28,47}$ and have suggested a role for Cx26 in both epidermal barrier establishment and cutaneous wound healing. ${ }^{30}$ Our study offers further evidence for the influence of Cx26 during cutaneous wound healing and illustrates a link between Cx26 disorders and aberrant keratinocyte differentiation. 


\section{Materials and Methods}

Genetically modified mice. The Animal Care Committee at Western University approved all animal experiments in accordance with guidelines from the Canadian Council for Animal Care. Cx26 $6^{\mathrm{CK} 14-\mathrm{S} 17 \mathrm{~F} /+}$ mice were generated in-house, on a mixed C57BL/6 and $129 \mathrm{~Sv}$ background. Heterozygous floxed mice (Cx26 $6^{\text {floxS17F/+ }}$ - generated by Schütz et al. and provided by the Bonn group) were crossed with homozygous cytokeratin 14 Cre mice (Gjb2 ${ }^{\text {tm2.2Kwi/Cnrm }}$, Jackson Labs) which were obtained from Dr. L. Dagnino. Therefore, S17F/+ mice would be expected to express Cx26S17F heterozygously in basal cells of the epidermis, as well as the dental epithelium and oral ectoderm. ${ }^{48} \mathrm{All}$ animal experiments used wildtype littermates as controls (referred to as Control). Efforts to generate homozygous CX26 $6^{\mathrm{CK} 14-\mathrm{S} 17 \mathrm{~F} / \mathrm{S} 17 \mathrm{~F}}$ failed, as these mice were not viable. Roughly equal proportions of male and female mice were used for all experiments.

Mouse genotyping. Briefly, ear notches at the time of weaning were incubated overnight at $58{ }^{\circ} \mathrm{C}$ in a proteinase $\mathrm{K}$ solution composed of $0.6 \mathrm{mg}$ of proteinase K (Cat\# 25530-049; Invitrogen, Carlsbad, CA, USA) dissolved in buffer containing $20 \mathrm{mM}$ Tris $\mathrm{Cl} \mathrm{pH} \mathrm{8.3,50} \mathrm{mM} \mathrm{KCl,} 2.5 \mathrm{mM} \mathrm{MgCl}$, and $0.5 \%$ Tween 20 . The digested tissue solution was incubated for $10 \mathrm{~min}$ at $95^{\circ} \mathrm{C}$ and DNA amplification was carried out by polymerase chain reaction (PCR). PCR mixtures included 10x PCR buffer (Cat\# 1360566; Invitrogen), 50 mM MgCl (Cat\# 11392196; Invitrogen), $10 \mu \mathrm{m}$ dNTPs (Cat\# 10297-018; Invitrogen), and Platinum Taq polymerase (Cat\# 10966-018; Invitrogen). Samples were run for 40 cycles with the annealing temperature set to $57{ }^{\circ} \mathrm{C}$. PCR products were run on a $2 \%$ agarose gel including $200 \mu \mathrm{g}$ of ethidium bromide, and gels were visualized under ultraviolet light.

Skeletal staining. Seven day old mice were euthanized, neatly eviscerated to reveal the skeleton, and the skeleton was stained according to a modified protocol from. ${ }^{49}$ Skeletons were dehydrated in $95 \%$ overnight and fixed in acetone for $24 \mathrm{~h}$. Skeletons were stained for 4 days using a solution containing $0.015 \%$ alcian blue, $0.05 \%$ alizarin red, and $5 \%$ acetic acid in $70 \%$ ethanol as described in Wang et al. ${ }^{50}$ Finally, skeletons were cleared using $1 \% \mathrm{KOH}$ in distilled water until the stained vertebrae and intervertebral disks were clearly visible. Two animals per genotype were used for skeletal staining.

Micro-computed tomography. Micro-computed tomography $(\mu \mathrm{CT})$ scans of euthanized 3-month-old S17F/+ and control whole mouse bodies were obtained using the eXplore speCZT $\mu \mathrm{CT}$ scanner (GE Healthcare Biosciences, Little Chalfont, UK) at Robarts Research Institute (London, ON, Canada) to assess the bone structure underlying the S17F/+ truncated tail or skeletal abnormalities in the digits. Further technical specifications and image processing techniques are outlined in Caskenette et al. ${ }^{51}$ Briefly, scans were acquired with a voxel size of $100 \mu \mathrm{m}^{3}$ and $3 \mathrm{D}$ composite isosurface images were constructed and manipulated using MicroView software (GE Healthcare Biosciences). One S17F/+ and one control mouse were used to create isosurface images.

Epidermal barrier assay. Neonatal epidermal barrier function was assessed as outlined in Schutz et al. ${ }^{25}$ Briefly, $\mathrm{P} 1$ neonates were $\mathrm{CO}_{2}$ euthanized and washed in a series of increasing methanol solutions (diluted in PBS) then submerged in an aqueous $0.2 \%$ toluidine blue solution for $15 \mathrm{~min}$. Pups were then washed $3 x$ in $90 \%$ ethanol and once in distilled water before examination. Areas of blue/purple staining indicated epidermal dye penetration from a defective water barrier. Intentional barrier disruption was performed by making a small incision to the skin, or by repeatedly treating the skin with an acetone soaked cotton swab as indicated in Tsai et al. ${ }^{26}$ Images were captured with an iPhone 5S.

Tissue lysates and immunoblotting. Foot pad skin was dissected, frozen with liquid nitrogen, and pulverized with a cold mortar and pestle over dry ice. Lysates were generated by dissolving the pulverized tissue in $2 x$ immunoprecipitation buffer (containing 1\% Triton X-100, $150 \mathrm{mM} \mathrm{NaCl}, 10 \mathrm{mM}$ Tris, $1 \mathrm{mM}$ EDTA, $1 \mathrm{mM}$ EGTA, $0.5 \%$ NP-40, phosphatase inhibitors $(1.0 \mathrm{mg}$ of NaF, $1.0 \mathrm{mg}$ of $\mathrm{Na}_{3} \mathrm{VO}_{4}$ ), and a Complete Mini protease inhibitor tablet (Cat\# 10570500 Roche, Basel, Switzerland). Lysates were stored at $-80^{\circ} \mathrm{C}$ until electrophoresis. Protein concentration was determined with a standard bicinchoninic acid assay (Cat\# 23225 , Pierce, Waltham, UK). Lysates were run on a $12 \%$ polyacrylamide gel using SDS-PAGE and protein was transferred to nitrocellulose membranes with the iBlot dry transfer system (7 min transfer). Membranes were blocked in 3\% BSA in PBST and probed with 1:1000 mouse anti-Cx26 (Cat\# 138100, Invitrogen), 1:1000 rabbit
anti-Cx30 (Cat\# 71-2200, Invitrogen), 1:5000 rabbit anti-Cx43 (Cat\# C6219, Sigma, St. Louis, MI, USA), 1:5000 mouse anti-GAPDH (Cat\# 2145925, Millipore, Billerica, MA), 1:1000 mouse anti-CK14 (Cat\# MA5-11599, ThermoFisher, Waltham, MA, USA), 1:1000 rabbit anti-filaggrin (Cat\# PRB-417P, Covance, Princeton, NJ), and 1:400 rabbit anti-proliferating cell nuclear antigen (PCNA) (Cat\# FL-261:Sc-7907, Santa Cruz, Dallas, TX) antibodies. Secondary antibodies included AlexaFluor680 (Cat\# A21076, Life Technologies, Carlsbad, CA, USA) and IRDye800 (Cat\# 24058, Rockland, Pottstown, Philadelphia, PE, USA) and membranes were visualized using the Odyssey infrared imaging system. An unpaired $t$-test was performed on the mean intensity ( $\mathrm{K}$ counts) of biological replicates.

Immunohistochemistry and immunofluorescence imaging. Foot pad skin was fixed with $10 \%$ neutral buffered formalin overnight at $4{ }^{\circ} \mathrm{C}$, paraffin embedded, sectioned, and stained with hematoxylin and eosin for histological analysis according to Stewart et al. ${ }^{52}$ Epidermal thickness measurements were recorded from histological images using ImageJ. Repaired dorsal epidermis was dissected 14 days following wounding and processed as described above. Sections were deparaffinized in xylene, and rehydrated in decreasing concentrations of ethanol $(100,95,90$, and $80 \%)$ then in distilled water. Sections were heated at $95^{\circ} \mathrm{C}$ in a $10 \mathrm{mM}$ sodium citrate buffer with $0.05 \%$ Tween $20(\mathrm{pH} 6.0)$ for $20 \mathrm{~min}$ and allowed to cool at room temperature before washing with PBST and incubating in $3 \%$ peroxidase blocking solution for $10 \mathrm{~min}$. Finally, sections were blocked for 30 min in 2\% BSA+0.2\% Triton X-100 and labeled with 1:200 mouse anti-cytokeratin 6 (Cat\# ab93279), 1:400 rabbit anti-Ki67 (Cat\# ab66155, Abcam, Cambridge, UK), 1:300 rat anti-CD4 (Cat\# 41-9766-080, ThermoFisher), mouse anti-CD68 (Cat\# MCA1957, BioRad, Hurcules, California), and rabbit anti-neutrophil elastase (Cat\# ab68672, Abcam). The secondary antibodies used were 1:500 anti-rabbit Alexa488 (Cat\# A11008, Life Technologies), 1:500 anti-rabbit Alexa555 (Cat\# A21429, Life Technologies), and 1:300 anti-rat Alexa555 (Cat\# A21434, Life Technologies).

Separate foot pad skin samples were also fixed, cryopreserved in $30 \%$ sucrose in PBS, embedded in $1 \%$ low melting point agarose containing $18 \%$ sucrose and $0.01 \%$ $\mathrm{NaN}_{3}$, flash frozen with liquid nitrogen, and cryosectioned for immunofluorescent imaging. Frozen sections were blocked in $2 \% \mathrm{BSA}+0.2 \%$ Triton X-100 and labeled with 1:400 rabbit anti-Cx26 (Cat\# 512800, Invitrogen), 1:400 rabbit anti-Cx30, 1:500 rabbit anti-Cx43, 1:200 mouse anti-cytokeratin 14, 1:200 rabbit anti-filaggrin, and 1:400 rabbit anti-Ki67. The secondary antibodies used were 1:500 anti-rabbit Alexa488, 1:500 anti-rabbit Alexa555, and 1:500 anti-mouse Alexa488 (Cat\# A11017, Life Technologies). Sections were counter-stained with Hoechst 33342, mounted using Airvol, and imaged with a Zeiss LSM 800 confocal microscope equipped with ZenWorks software. Images were captured from at least 3 biological replicates with a $40 \times$ water-immersion objective.

Wound healing assay. Three-month-old mice were anesthetized with isoflurane, administered the analgesics ketoprofen $(5 \mathrm{mg} / \mathrm{kg}$ body weight) and buprenorphine ( $15 \mathrm{mg} / \mathrm{kg}$ body weight) subcutaneously, then a small section of dorsal hair was shaved and depilated with Nair, and the skin was sterilized using the standard 3-stage preparation. Wounds were performed using a $5 \mathrm{~mm}$ human punch biopsy to remove the full thickness of the skin as described in Churko et al. ${ }^{53}$ Briefly, dorsal skin was held taut and a punch biopsy tool was twisted on the skin with light pressure until a full thickness circle of skin was removed. Skin tension was released and allowed to retract for $\sim 30 \mathrm{~s}$ before imaging. Wound inspection and imaging was performed the day of surgery, and every second day until fully healed. Wound sizes were measured using ImageJ by an investigator blinded to the mouse genotypes. A two-way ANOVA with repeated measures was performed on the mean wound area of biological replicates.

Cell lines. Rat epidermal keratinocytes (REKs) originally described in Baden and Kubilus ${ }^{54}$ were provided by Dr. V. Hascall and verified as keratinocytes in that they could stratify to form organotypic epidermis. Cells were grown in DMEM (Cat\# 11965-092, Life Technologies) containing $4.5 \mathrm{~g} / \mathrm{l}$ glucose supplemented with $10 \%$ fetal bovine serum (Cat\# 12484-028, Invitrogen), 2 mM L-glutamine (Cat\# 25030081, Life Technologies), 100 units $/ \mathrm{ml}$ penicillin, and $100 \mu \mathrm{g} / \mathrm{ml}$ streptomycin (Invitrogen). Cells were incubated at $37{ }^{\circ} \mathrm{C}$ and $5 \% \mathrm{CO}_{2}{ }^{55}$

Primary murine keratinocyte culture. Keratinocytes were isolated from neonatal mice (P2-P3) according to Churko et al. ${ }^{16}$ with minor procedural adjustments. Briefly, complete body skin was carefully dissected from neonates was rinsed in $\mathrm{Ca}^{2+}$ and $\mathrm{Mg}^{2+}$ free PBS (Cat\# 14190-144, Invitrogen) containing $5 \mu \mathrm{g} / \mathrm{ml}$ gentamycin (Cat\# 15750-060, Invitrogen). Skins were floated dermis side down over 
$1.5 \mathrm{ml}$ of $50 \mathrm{cU} / \mathrm{ml}$ dispase (Cat\#354235, Corning) at $4{ }^{\circ} \mathrm{C}$ overnight with gentle rocking. The epidermis was gently separated from the dermis, minced with sterile scissors, and incubated in 0.25\% trypsin-EDTA (Cat\# 25200-056, Invitrogen) for $\sim 10 \mathrm{~min}$ at $37^{\circ} \mathrm{C}$. The cell suspension was removed and placed into $1.5 \mathrm{ml}$ of Keratinocyte Serum-Free Medium (K-SFM) (Cat\# 37010-022, Invitrogen) supplemented with $1.4 \mathrm{mM} \mathrm{CaCl}_{2}$ and $1.5 \mathrm{ml}$ of stock trypsin neutralizer solution (Cat\# R-002-100, Invitrogen), and centrifuged. The pellet was resuspended in K-SFM supplemented with $0.05 \mathrm{mM} \mathrm{CaCl}_{2}$, poured through a $70 \mu \mathrm{m}$ cell strainer (Cat\# 21008-952, Falcon, Waltham, MA, USA), and plated in dishes pre-coated with $50 \mu \mathrm{g} / \mathrm{ml}$ collagen I (Cat\# 354236, BD Biosciences, San Jose, CA, USA). The next day, cells were washed 2 times with $\mathrm{Ca}^{2+}$ and $\mathrm{Mg}^{2+}$ free PBS then incubated in K-SFM containing $1.4 \mathrm{mM} \mathrm{CaCl}_{2}$. Cells were used for experiments between 48$72 \mathrm{~h}$ following initial plating.

Calcein-AM dye recovery. Approximately $1 \times 10^{6}$ primary mouse keratinocytes or REKs were grown on $35 \mathrm{~mm}$ glass bottom dishes (Cat\# D35-14-1-U, Matsunami, Bellingham, Washington) and pre-loaded for $10 \mathrm{~min}$ at $37^{\circ} \mathrm{C}$ in an isotonic $0.3 \mathrm{mM}$ glucose solution containing $2 \mu \mathrm{l} / \mathrm{ml}$ calcein-AM (Cat\# C3100MP, Molecular Probes, Eugene, Oregon) dissolved in DMSO (Cat\# D2650, SigmaAldrich). Cells were washed in PBS, replenished with K-SFM, and photobleached to $<20 \%$ of original fluorescence intensity with a $488 \mathrm{~nm}$ argon laser at $50 \%$ strength. Images were subsequently captured every $10 \mathrm{~s}$ for $\sim 10 \mathrm{~min}$ with a LSM 800 Zeiss confocal microscope and a $40 \times$ water-immersion lens. A minimum of three images series (in which multiple cells were photobleached) were performed for each experiment. Each image series was exported to ImageJ and fluorescence recovery of photobleached cells were measured using the Time Series Analyzer V3 plugin. Fluorescence recovery curves displayed summarized data and a two-tailed student's $t$-test was performed on the mean area under the curve (AUC) of biological replicates.

Scratch-wound assay. Primary mouse keratinocytes were seeded at $1 \times 10^{6}$ cells per $35 \mathrm{~mm}$ gridded dish (Cat\# 83.1800.001, Sarstedt, Nümbrecht, Germany). Culture dishes were pre-coated with collagen as previously described and following $48 \mathrm{~h}$ of incubation in K-SFM containing $1.4 \mathrm{mM} \mathrm{CaCl}$, cells were rinsed with $\mathrm{Ca}^{2+}$ and $\mathrm{Mg}^{2+}$ free PBS and scraped with a P1000 pipette tip. Cells were then replenished with K-SFM containing no supplements or $\mathrm{CaCl}_{2}$ and images of 10 identical sections per dish $\left(0.5 \mathrm{~mm}^{2}\right)$, were captured at 24 and $48 \mathrm{~h}$ following the scrape. For each image, the gap between keratinocyte fronts was measured in five similar regions and an unpaired $t$-test was performed on the calculated migration distances of biological replicates.

Statistical analysis. Graph Pad Prism version 6 was used for all statistical analysis and statistical significance was noted when $P<0.05$. All student's t-tests were two-tailed. All histogram values represent the mean+S.E.M.

\section{Conflict of Interest}

The authors declare no conflict of interest.

Acknowledgements. We would like to thank Dr Katherine Willmore, Joseph Umoh, and Dr David Holdsworth for helping generate the $\mu \mathrm{CT}$ images as well as Dawn Marie Bryce for assistance with the skeletal staining technique. We would also like to thank Charles Walewski, Tamara Abood, Layo Alaga, and Ruichen Shang for assisting with image quantification. This research was supported by a Canadian Institutes of Health Research grant (123228) to DWL. The generation of mouse lines by the Bonn group had been supported by the German Research Foundation through SFB645 B2.

\section{Author contributions}

ERP performed all experiments with assistance from KCA for $\mathrm{Cx} 26^{\mathrm{CK} 14-\mathrm{S} 17 \mathrm{~F} / \mathrm{+}}$ mouse characterization and the epidermal barrier assay. KB established the $\mathrm{C} \times 26^{\mathrm{CK} 14-\mathrm{S} 17 \mathrm{~F} /+}$ mouse line. $\mathrm{FB}$ and $\mathrm{KW}$ provided the $\mathrm{C} \times 26^{\text {floxS17F/+ }}$ mouse line. ERP, QS and DWL designed the experiments. ERP drafted the manuscript. DWL edited the manuscript.

1. Alexander DB, Goldberg GS. Transfer of biologically important molecules between cells through gap junction channels. Curr Med Chem 2003; 10: 2045-58.
2. Sáez JC, Retamal MA, Basilio D, Bukauskas FF, Bennett MVL. Connexin-based gap junction hemichannels: gating mechanisms. Biochim Biophys Acta 2005; 1711: 215-24.

3. Avshalumova L, Fabrikant J, Koriakos A. Overview of skin diseases linked to connexin gene mutations. Int J Dermatol 2014; 53: 192-205.

4. Lilly $E$, Sellitto $C$, Milstone LM, White TW. Connexin channels in congenital skin disorders Semin Cell Dev Biol 2016; 50: 4-12.

5. Martin PE, van Steensel M. Connexins and skin disease: insights into the role of beta connexins in skin homeostasis. Cell Tissue Res 2015; 360: 645-58.

6. Scott CA, Tattersall D, O'Toole EA, Kelsell DP. Connexins in epidermal homeostasis and skin disease. Biochim Biophys Acta 2012; 1818: 1952-61.

7. Xu J, Nicholson BJ. The role of connexins in ear and skin physiology - functional insights from disease-associated mutations. Biochim Biophys Acta 2013; 1828: 167-78.

8. Yum SW, Zhang JX, Valiunas V, Kanaporis G, Brink PR, White TW et al. Human connexin26 and connexin30 form functional heteromeric and heterotypic channels. Am J Physiol 2007; 293: C1032-C48.

9. Di WL, Rugg EL, Leigh IM, Kelsell DP. Multiple epidermal connexins are expressed in different keratinocyte subpopulations including connexin 31. J Invest Dermatol 2001; 117: 958-64.

10. Adams MP, Mallet DG, Pettet GJ. Active regulation of the epidermal calcium profile. J Theor Biol 2012; 301: 112-21.

11. Bikle DD, Xie Z, Tu CL. Calcium regulation of keratinocyte differentiation. Expert Rev Endocrinol Metab 2012; 7: 461-72.

12. Bosen F, Celli A, Crumrine D, vom Dorp K, Ebel P, Jastrow $\mathrm{H}$ et al. Altered epidermal lipid processing and calcium distribution in the KID syndrome mouse model Cx26S17F. FEBS Lett 2015; 589: 1904-10.

13. Sandilands $A$, Sutherland $C$, Irvine $A D$, McLean WH. Filaggrin in the frontline: role in skin barrier function and disease. J Cell Sci 2009; 122: 1285-94.

14. Brandner JM, Houdek P, Husing B, Kaiser C, Moll I. Connexins 26, 30, and 43: differences among spontaneous, chronic, and accelerated human wound healing. $J$ Invest Dermatol 2004; 122: 1310-20.

15. Churko JM, Laird DW. Gap junction remodeling in skin repair following wounding and disease. Physiology 2013; 28: 190-8.

16. Churko JM, Kelly JJ, Macdonald A, Lee J, Sampson J, Bai D et al. The G60S Cx43 mutant enhances keratinocyte proliferation and differentiation. Exp Dermatol 2012; 21: 612-8.

17. Coutinho P, Qiu C, Frank S, Tamber K, Becker D. Dynamic changes in connexin expression correlate with key events in the wound healing process. Cell Biol Int 2003; 27 525-41.

18. Ghatnekar GS, Grek CL, Armstrong DG, Desai SC, Gourdie RG. The effect of a connexin43based Peptide on the healing of chronic venous leg ulcers: a multicenter, randomized trial. J Invest Dermatol 2015; 135: 289-98.

19. Mori R, Power KT, Wang CM, Martin P, Becker DL. Acute downregulation of connexin 43 at wound sites leads to a reduced inflammatory response, enhanced keratinocyte proliferation and wound fibroblast migration. J Cell Sci 2006; 119: 5193-203.

20. Qiu C, Coutinho P, Frank S, Franke S, Law LY, Martin P et al. Targeting connexin43 expression accelerates the rate of wound repair. Curr Biol 2003; 13: 1697-703.

21. Coggshall K, Farsani T, Ruben B, McCalmont TH, Berger TG, Fox LP et al. Keratitis, ichthyosis, and deafness (KID) syndrome: a review of infectious and neoplastic complications. J Am Acad Dermatol 2013; 69: 127-34.

22. García IE, Maripillán J, Jara O, Ceriani R, Palacios-Muñoz A, Ramachandran J et al. Keratitis-ichthyosis-deafness syndrome-associated Cx26 mutants produce nonfunctional gap junctions but hyperactive hemichannels when co-expressed with wild type Cx43. J Invest Dermatol 2015; 135: 1338-47.

23. Lee JR, Derosa AM, White TW. Connexin mutations causing skin disease and deafness increase hemichannel activity and cell death when expressed in Xenopus oocytes. $J$ Invest Dermatol 2009; 129: 870-8.

24. Richard G, Rouan F, Willoughby CE, Brown N, Chung P, Ryynanen M et al. Missense mutations in GJB2 encoding connexin-26 cause the ectodermal dysplasia keratitisichthyosis-deafness syndrome. Am J Hum Genet 2002; 70: 1341-8.

25. Schütz M, Auth T, Gehrt A, Bosen F, Körber I, Strenzke N et al. The connexin26 S17F mouse mutant represents a model for the human hereditary keratitis-ichthyosis-deafness syndrome. Hum Mol Genet 2011; 20: 28-39.

26. Tsai JC, Sheu HM, Hung PL, Cheng CL. Effect of barrier disruption by acetone treatment on the permeability of compounds with various lipophilicities: implications for the permeability of compromised skin. J Pharm Sci 2001; 90: 1242-54.

27. van Steensel MA. Gap junction diseases of the skin. Am J Med Genet C Semin Med Genet 2004; 131C: $12-9$.

28. Bakirtzis G, Choudhry R, Aasen T, Shore L, Brown K, Bryson S et al. Targeted epidermal expression of mutant Connexin 26(D66H) mimics true Vohwinkel syndrome and provides a model for the pathogenesis of dominant connexin disorders. Hum Mol Genet 2003; 12 : 1737-44

29. Cogliati B, Vinken M, Silva TC, Araújo CM, Aloia TP, Chaible LM et al. Connexin 43 deficiency accelerates skin wound healing and extracellular matrix remodeling in mice. J Dermatol Sci 2015; 79: 50-6.

30. Djalilian AR, McGaughey D, Patel S, Seo EY, Yang C, Cheng J et al. Connexin 26 regulates epidermal barrier and wound remodeling and promotes psoriasiform response. J Clin Invest2006; 116: 1243-53. 
31. Maass K, Ghanem A, Kim JS, Saathoff M, Urschel S, Kirfel G et al. Defective epidermal barrier in neonatal mice lacking the C-terminal region of connexin43. Mol Biol Cell 2004; 15 : 4597-608.

32. Mese G, Sellitto C, Li L, Wang HZ, Valiunas V, Richard G et al. The Cx26-G45E mutation displays increased hemichannel activity in a mouse model of the lethal form of keratitisichthyosis-deafness syndrome. Mol Biol Cell 2011; 22: 4776-86.

33. Lamartine J, Munhoz Essenfelder G, Kibar Z, Lanneluc I, Callouet E, Laoudj D et al. Mutations in GJB6 cause hidrotic ectodermal dysplasia. Nat Genet 2000; 26: 142-4.

34. Gerido DA, DeRosa AM, Richard G, White TW. Aberrant hemichannel properties of Cx26 mutations causing skin disease and deafness. Am J Physiol Cell Physiol 2007; 293: C337-45.

35. Maestrini E, Korge BP, Ocaña-Sierra J, Calzolari E, Cambiaghi S, Scudder PM et al. A missense mutation in connexin26, D66H, causes mutilating keratoderma with sensorineura deafness (Vohwinkel's syndrome) in three unrelated families. Hum Mol Genet 1999; 8: 1237-43.

36. Gabriel HD, Jung D, Bützler C, Temme A, Traub O, Winterhager E et al. Transplacental uptake of glucose is decreased in embryonic lethal connexin26-deficient mice. J Cell Bio 1998; 140: 1453-61.

37. Bao L, Sachs F, Dahl G. Connexins are mechanosensitive. Am J Physiol Cell Physiol 2004 287: C1389-95.

38. Baroja-Mazo A, Barberá-Cremades M, Pelegrín P. The participation of plasma membrane hemichannels to purinergic signaling. Biochim Biophys Acta 2013; 1828: 79-93.

39. Martin PE, Easton JA, Hodgins MB, Wright CS. Connexins: sensors of epidermal integrity that are therapeutic targets. FEBS Lett 2014; 588: 1304-14.

40. Martin P. Wound healing-aiming for perfect skin regeneration. Science 1997; 276: 75-81.

41. Mendoza-Naranjo A, Cormie P, Serrano AE, Hu R, O'Neill S, Wang CM et al. Targeting Cx43 and $\mathrm{N}$-cadherin, which are abnormally upregulated in venous leg ulcers, influences migration, adhesion and activation of Rho GTPases. PLoS One 2012; 7: e37374.

42. Henzl MT, Thalmann I, Larson JD, Ignatova EG, Thalmann R. The cochlear F-box protein OCP1 associates with OCP2 and connexin 26. Hear Res 2004; 191: 101-9.

43. Davis NG, Phillips A, Becker DL. Connexin dynamics in the privileged wound healing of the buccal mucosa. Wound Repair Regen 2013; 21: 571-8.

44. Goliger JA, Paul DL. Wounding alters epidermal connexin expression and gap junctionmediated intercellular communication. Mol Biol Cell 1995; 6: 1491-501.

45. Kretz M, Euwens C, Hombach S, Eckardt D, Teubner B, Traub $\mathrm{O}$ et al. Altered connexin expression and wound healing in the epidermis of connexin-deficient mice. J Cell Sci 2003; 116: 3443-52.

46. Giamboi-Miraglia A, Cianfarani F, Cattani C, Lena AM, Serra V, Campione E et al. The E3 ligase Itch knockout mice show hyperproliferation and wound healing alteration. FEBS $J$ 2015; 282: 4435-49.
47. Mese G, Sellitto C, Li LP, Wang HZ, Valiunas V, Richard G et al. The Cx26-G45E mutation displays increased hemichannel activity in a mouse model of the lethal form of keratitisichthyosis-deafness syndrome. Mol Biol Cell 2011; 22: 4776-86.

48. Dassule HR, Lewis $P$, Bei M, Maas R, McMahon AP. Sonic hedgehog regulates growth and morphogenesis of the tooth. Development 2000; 127: 4775-85.

49. McLeod MJ. Differential staining of cartilage and bone in whole mouse fetuses by alcian blue and alizarin red S. Teratology 1980; 22: 299-301.

50. Wang GY, Woods A, Agoston H, Ulici V, Glogauer M, Beier F. Genetic ablation of Rac1 in cartilage results in chondrodysplasia. Dev Biol 2007; 306: 612-23.

51. Caskenette D, Penuela S, Lee V, Barr K, Beier F, Laird DW et al. Global deletion of Panx3 produces multiple phenotypic effects in mouse humeri and femora. $J$ Anat 2016; 228: $746-56$.

52. Stewart MKG, Gong XQ, Barr KJ, Bai DL, Fishman GI, Laird DW. The severity of mammary gland developmental defects is linked to the overall functional status of $\mathrm{Cx} 43$ as revealed by genetically modified mice. Biochem J 2013; 449: 401-13.

53. Churko JM, Shao Q, Gong XQ, Swoboda KJ, Bai D, Sampson J et al. Human dermal fibroblasts derived from oculodentodigital dysplasia patients suggest that patients may have wound-healing defects. Hum Mutat 2011; 32: 456-66.

54. Baden HP, Kubilus J. The growth and differentiation of cultured newborn rat keratinocytes. $J$ Invest Dermatol 1983; 80: 124-30.

55. Ableser MJ, Penuela S, Lee J, Shao Q, Laird DW. Connexin43 reduces melanoma growth within a keratinocyte microenvironment and during tumorigenesis in vivo. J Biol Chem 2014; 289: 1592-603.

(1) Cell Death and Disease is an open-access journal published by Nature Publishing Group. This work is licensed under a Creative Commons Attribution 4.0 International License. The images or other third party material in this article are included in the article's Creative Commons license, unless indicated otherwise in the credit line; if the material is not included under the Creative Commons license, users will need to obtain permission from the license holder to reproduce the material. To view a copy of this license, visit http://creativecommons.org/licenses/by/4.0/

(C) The Author(s) 2017

Supplementary Information accompanies this paper on Cell Death and Disease website (http://www.nature.com/cddis) 